\title{
Moderate Asymptomatic Subacute Eosinophilia Secondary to Simvastatin Therapy
}

de las Marinas Alvarez MD ${ }^{1}$, López Calatayud V', Solaz Garrido $\mathrm{B}^{2}$, Catalá Bauset $\mathrm{M}^{3}$, Montesinos Carbonell $\mathrm{M}^{4}$, Albert Sánchez $\mathrm{P}^{5}$

${ }^{1}$ Department of Allergology, Policlínico Valencia, Valencia, Spain ${ }^{2}$ Digestive Medicine Department, Policlínico Valencia, Valencia, Spain

${ }^{3}$ Endocrinology Department, Policlínico Valencia, Valencia, Spain ${ }^{4}$ Gynecology Department, Policlínico Valencia, Valencia, Spain ${ }^{5}$ Clinical Analysis Laboratory, Policlínico Valencia, Valencia, Spain

J Investig Allergol Clin Immunol 2018; Vol. 28(6): 434-436 doi: 10.18176/jiaci.0312

Key words: Simvastatin. Drug-induced eosinophilia. Asymptomatic eosinophilia.

Palabras clave: Simvastatina. Eosinofilia inducida por medicamentos. Eosinofilia asintomática.

In allergological practice, we often see patients with serum eosinophil counts above normal. These elevations are generally mild and are easily related to an atopic background. We also see patients requiring a differential diagnosis owing to eosinophilia of indeterminate origin. The present case seeks to alert clinicians to the need to investigate the etiology of casually identified eosinophilia, particularly with the purpose of diagnosing underlying disorders that are not clinically manifest at the time (eg, proliferative syndromes, parasitoses, drugs, autoimmune diseases) and could cause collateral damage owing to eosinophilic infiltration of various tissues if not adequately treated. In general, all cases of moderate to severe eosinophilia persisting for over 6 months should be monitored through laboratory tests and echocardiography, with administration of adequate corrective treatment, even cytoreductive medication [1-3].

We present the case of a 28 -year-old woman who consulted owing to the casual identification of marked eosinophilia $(3000 / \mu \mathrm{L}, 40 \%)$ in a blood count requested by her gynecologist for the evaluation of an ovarian cyst that was casually detected during a routine annual ultrasound exploration. The blood count was repeated 1 week later, with a manual reading of the blood smear, and confirmed persistent eosinophilia of similar magnitude $(2980 / \mu \mathrm{L}, 36.6 \%)$. The case history showed that the eosinophil counts had always been under $200 / \mu \mathrm{L}$ in previous years. The patient therefore consulted the allergology clinic, where a detailed history was taken, with assessment of the most common possible causes (especially atopic disease and parasitic infestation). She reported having had mild symptoms of nonseasonal rhinitis for several years and mild dyspepsia, with no malaise, altered bowel habit, weight loss, fever, or other signs or symptoms of systemic disease or abnormalities associated with infiltration of organs by eosinophils. The 
patient had travelled to South America 18 months previously and had a dog at home. She received regular medication in the form of oral contraceptives, levothyroxine due to hypothyroidism (for the previous 6 years), and simvastatin prescribed by the endocrinologist 2 months previously because of hypercholesterolemia.

Complementary tests were requested mainly to rule out atopic disease, hematological disorders, autoimmune disease, liver disease, lung disease, and parasitic infestation capable of accounting for the eosinophilia. Possible implication of the ovarian cyst was also evaluated, and a differential diagnosis with hydatid cyst at an uncommon location was established. The studies included skin testing of common aeroallergens in our setting (ie, latex, lipid transfer protein, profilin, and Anisakis [with negative results, negative control saline solution, and histamine reaction of $7 \mathrm{~mm}]$ ), full biochemical profile (liver and kidney function, iron metabolism), serum immunoglobulins, protein profile, antinuclear antibodies, and anti-DNA antibodies, Strongyloides and hydatidosis serology, urine sediment, serial stool parasite study, total $\operatorname{IgE}(75 \mathrm{kU} / \mathrm{L})$, serum tryptase, chest $\mathrm{x}$-rays, and abdominal ultrasound. Several biopsy specimens were obtained using esophagogastroscopy, and follow-up of the ovarian cyst with determination of levels of luteinizing hormone, folliclestimulating hormone, and various ovarian carcinomatosis markers was prescribed. All the results were within normal limits except for simple liver cysts that were not suggestive of hydatidosis. The ovarian cyst disappeared with the following menstrual period.

Furthermore, in order to rule out drug treatment as a causal factor of eosinophilia, simvastatin was suspended, and follow-up was based on serial blood counts and monitoring of cholesterol levels. The blood count obtained 2 weeks after drug suspension revealed a clear decrease in eosinophil count $(430 / \mu \mathrm{L}, 8.9 \%)$, and, 2 weeks later, the count was seen to have returned to normal $(180 / \mu \mathrm{L}, 4.8 \%)$, with no alteration of the concentration of cholesterol $(187 \mathrm{mg} / \mathrm{dL})$ or its fractions. The patient rejected the reintroduction of statin therapy to assess possible repetition of eosinophilia.

Many cases of mild eosinophilia $(400-1500 / \mu \mathrm{L})$ are casual findings and tend to resolve spontaneously. Nevertheless, it is considered essential to rule out a number of possible diseases such as allergic disorders with respiratory and/or cutaneous manifestations, drug allergies, parasitoses, cancer, adrenal gland insufficiency, connective tissue disease, and HIV infection. Likewise, possible eosinophilia of indeterminate origin should be contemplated in the case of moderate $(1500-5000 \mu \mathrm{L})$ to severe eosinophilia $(>5000 \mu \mathrm{L})$, with due evaluation and treatment [1-3]. The diagnosis therefore requires a detailed history and physical examination, with complementary laboratory tests (kidney and liver function), chest x-ray, abdominal ultrasound, parasitic and viral serology, immune activity studies, and the detection of autoantibodies according to the clinical suspicion in each case [1-3]. On the other hand, a number of case series involving prolonged follow-up periods have reported persistently asymptomatic eosinophilia $(>1500 \mu \mathrm{L})$, such cases being regarded as benign disorders or hypereosinophilia of unknown significance [4].
The drugs most commonly associated with the induction of eosinophilia are $\beta$-lactam antibiotics, tetracyclines, nonsteroidal antiinflammatory drugs, ranitidine, allopurinol, sulfasalazine, carbamazepine, cyclosporine, hydrochlorothiazide, and phenytoin [1-3]. The adverse reactions most frequently described in relation to lipid-lowering medications are gastrointestinal discomfort, myositis or rhabdomyolysis, neurological alterations, skin rash [5], angioedema [6], and pneumonitis [7]. Hampson et al [6] reported episodes of anaphylaxis (angioedema and hypotension) associated with eosinophilia following the administration of atorvastatin, probably involving an IgE-mediated mechanism. The prevalence of allergic sensitization to statins is estimated to be $0.1 \%[7,8]$.

A review of the literature shows the present report to be the first to describe a case of asymptomatic eosinophilia due to simvastatin therapy. Tang et al [9] reported a case of prolonged (4 months) eosinophilia in relation to atorvastatin use, with secondary eosinophilic infiltration of the intestinal tissues causing moderate abdominal pain. Both alterations disappeared after suspending treatment.

The way in which simvastatin caused peripheral eosinophilia in the case we report is not clear. According to Cozzani et al [10], atorvastatin may have activated the STAT3 signaling pathway.

On the other hand, although the possibility of crossreactivity between the different statins has not been established, some of the patients tolerated statins (rosuvastatin) other than the drug implicated in the initial adverse reaction $[9,10]$. In the case we report, fibrates will be prescribed if necessary. Initiation of rosuvastatin may be considered later, with close monitoring of the eosinophil count.

\section{Funding}

The authors declare that no funding was received for the present study.

\section{Conflicts of Interest}

The authors declare that they have no conflicts of interest.

\section{References}

1. Tefferi A. Blood eosinophilia: a new paradigm in disease classification, diagnosis and treatment. Mayo Clin Proc. 2005;80:75-83.

2. Valent $P$, Klion $A D$, Rosenwasser $L J$, Arock $M$, Bochner BS, Butterfield JH, et al. ICON: Eosinophil Disorders. World Allergy Organ J. 2012;5:174-81.

3. Valent P, Klion AD, Horny HP, Roufosse F, Gotlib J, Weller $\mathrm{PF}$, et al. Contemporary consensus proposal on criteria and classification of eosinophilic disorders and related syndromes. JACI. 2012;130:607-12.

4. Chen YY, Khoury P, Ware JM, Holland-Thomas NC, Stoddard JL, Gurprasad S, et al. Marked and persistent eosinophilia in the absence of clinical manifestations. JACI. 2014;133:1195-202.

5. Gressier L, Pruvost-Balland C, Dubertret L, Viguier $M$. [Atorvastatin-induced drug reaction with eosinophilia 
and systemic symptoms (DRESS)]. Ann Dermatol Venereol. 2009;136(1):50-3.

6. Hampson JP, Smith D, Cowell R, Baker A. Hypotension and eosinophilia with atorvastatin. Pharm World Sci. 2005;27:27980.

7. Liebhaber MI, Wright RS, Gelberg HJ Kupperman JL. Polymyalgia, hypersensitivity pneumonitis and other reactions in patients receiving HMG-CoA reductase inhibitors: a report of ten cases. Chest. 1999;115:886-9.

8. Fosso CK. Adverse effects of 3-hydroxy-3-methylglutaryl coenzyme $A$ reductase inhibitors associated with elevated serum $\lg \mathrm{E}$ and eosinophilia. J Allergy Clin Immunol. 1995;95(5):1053.

9. Tang R, Chen S, Zhang HY. One case of eosinophilia caused by atorvastatin. Chin Med J (Engl). 2013;126:3994.

10. Cozzani E, Scaparro M, Parodi A. A case of psoriasis worsened by atorvastatin. J of Dermatol Case Rep. 2009;4:60-1.

Manuscript received August 12, 2018; accepted for publication August 30, 2018.

María Dolores de las Marinas Alvarez

Policlínico Valencia Valencia, Spain

E-mail: ddelasma@yahoo.es 